\title{
Gas migration experiments in bentonite: implications for numerical modelling
}

\author{
C. C. Graham ${ }^{1}$ **, J. F. Harrington ${ }^{1}$, R. J. Cuss ${ }^{1}$ and P. Sellin ${ }^{2}$ \\ 1 British Geological Survey, Keyworth, Nottingham NG12 5GG, UK \\ 2 SKB, Stockholm, Sweden
}

[Received 20 February 2012; Accepted 19 November 2012; Associate Editor: Nicholas Evans]

\section{ABSTRACT}

In the Swedish KBS-3 repository concept, there is potential for gas to be generated from corrosion of ferrous materials under anoxic conditions, combined with the radioactive decay of the waste and radiolysis of water. A full understanding of the probable behaviour of this gas phase within the engineered barrier system (EBS) is therefore required for performance assessment. We demonstrate key features from gas transport experiments on pre-compacted $\mathrm{Mx} 80$ bentonite, under laboratory and field conditions, and discuss their implications in terms of a conceptual model for gas migration behaviour. On both scales, major gas entry is seen to occur close to the sum of the porewater and swelling pressures of the bentonite. In addition, gas pressure at breakthrough is profoundly sensitive to the number and location of available sinks for gas escape. Observations of breakthrough can be explained by the creation of dilatational pathways, resulting in localized changes in the monitored porewater pressures and total stresses. These pathways are highly unstable, evolving spatially and temporally, and must consequently influence the gas permeability as their distribution/geometry develops.

Such observations are poorly embodied by conventional concepts of two-phase flow, which do not fully represent the key processes involved. Although dilatancy based models provide a better description of these processes, the paucity of data limits further development and validation of these models at present.

KEYWORDs: bentonite, engineered barrier systems, gas migration, geological disposal, pathway dilation, radioactive waste.

\section{Introduction}

IN the Swedish KBS-3 repository concept, copper canisters containing spent nuclear fuel will be placed in large-diameter disposal boreholes drilled into the floor of the repository tunnels. The space around each canister will be filled with pre-compacted bentonite blocks, which will swell upon infiltration by the surrounding groundwater, closing construction joints. As part of the safety case for this concept, the potential for hydrogen

* E-mail: caro5@bgs.ac.uk

DOI: 10.1180/minmag.2012.076.8.41 generation as a result of canister corrosion and radiolysis of water, and its probable impact on the bentonite buffer, must be considered. Depending on the rates of gas production and diffusion through the bentonite, it is possible that gas will accumulate in the void-space of each canister (Horseman, 1996; Horseman et al., 1997, 1999; SKB, 2011).

In order to gain a complete understanding of the advective flow behaviour of gas within the buffer, gas injection experiments can be performed on a range of scales to investigate the processes and controlling factors in such a scenario. In particular, knowledge of the dominant mechanism for advective gas migration is 
required to assess the buffer performance and address a number of questions. At what gas pressure will gas enter the buffer? Does flow occur in a localized fashion or is it distributed through the matrix of the bentonite? Will the spatial distribution of fractures within the borehole (acting as sinks for gas escape) be of significance?

Some of the earliest papers on gas migration in compact bentonite, relating to radioactive waste disposal, were published by Pusch and co-workers in Sweden. The gas permeability of saturated Mx80 bentonite following gas breakthrough was examined by Pusch and Forsberg (1983). After gas had passed through the clay, the degree of saturation of specimens was found to still be close to $100 \%$, indicating that the gas must have been transported in a localized fashion. Eight tests were carried out on saturated Mx80 specimens by Pusch et al. (1985). The gas pressure was incrementally increased at one to five day intervals, until advective gas outflow was observed at the downstream end of the sample at some critical value of pressure, which was noted to be of the same order of magnitude as the swelling pressure, П. This critical threshold is now generally known as the 'gas breakthrough pressure'. A further critical threshold also exists, the 'gas entry pressure', which is the value at which gas is first observed to enter the material. However, as experimental determination of gas entry is not trivial, laboratory studies commonly test for the gas breakthrough pressure instead. References to gas entry and gas breakthrough within the following text relate to these definitions.

A programme of gas migration experiments is also presented by Gallé (1998) and Gallé and Tanai (1998) for Fo-Ca (Fourges-Cahaignes) clay (consisting predominantly of calcium smectite with interstratified kaolinite-beidellite, compacted to a range of dry densities from $1600-1900 \mathrm{~kg} \mathrm{~m}^{-3}$ ). A number of the samples were back-pressured with water at a pressure above atmospheric, to examine the behaviour of saturated clay. The tests involved raising the gas pressure at one end of the specimen in increments. Gallé and Tanai (1998) observed two distinct thresholds. In contrast to the terms used in this paper (described above), the authors described the gas pressure at the lower threshold as the gas entry pressure, which coincides with the first appearance of gas at the downstream end of the specimen (i.e. the value equivalent to the gas breakthrough pressure as described above). The upper threshold was characterized by a sharp increase in measured flow rate and was termed breakthrough pressure by the authors. Although this breakthrough pressure was always greater than the gas entry pressure, in the fully saturated clay these two thresholds were observed to be very close. In addition the gas permeability of FoCa clay was found to decrease systematically for increasing degree of saturation or dry density.

The relationship between dry density, swelling pressure and breakthrough pressure of saturated Kunigel VI and French Fo-Ca clay was examined by Tanai et al. (1997). Samples of a known dry density $\left(1600,1700\right.$ and $\left.1800 \mathrm{~kg} \mathrm{~m}^{-3}\right)$ were subjected to a fixed head of water, supplied through the lower porous disc of an oedometer cell. An initial hydrogen gas pressure of $0.5 \mathrm{MPa}$ was applied to the lower surface of the specimen and it was raised in increments of $0.5 \mathrm{MPa}$ (applied at time intervals of $120 \mathrm{~h}$ ). The detected breakthrough pressures were observed to be close to the measured swelling pressures for both clay types.

An additional programme of gas injection testing was carried out by Donohew et al. (2000), on unconfined and initially watersaturated clay pastes. They investigated the relationships between gas entry pressure, water content and plasticity for a range of clay types. The aim was to define the principal mechanisms of gas entry and flow by simple visual observations, and to determine the effects of previous gas injection and residual gas content on entry pressure. None of these tests provided any observations indicating that gas actually penetrated or flowed through the intergranular porosity of the clay matrix. Instead, gas was observed in all cases to make its own volume, by pushing back the paste and lifting the free surface of the sample. Remnant gas-filled voids and cracks were observed within the clay after gas injection. During repeated injections these were observed to reopen at pressures which were only a fraction of the original entry pressures for the gas-free pastes.

A series of controlled flow rate gas-injection experiments on pre-compacted Mx80 buffer bentonite were reported by Horseman et al. (1997, 1999) and Harrington and Horseman (1999). Samples were fully saturated (>99\%) and equilibrated under an isotropically applied confining stress with an external water pressure of 1.0 $\mathrm{MPa}$ applied at both ends. Helium was used as a permeant, and injected at a constant flow rate. 
Test Mx80-4 (a sample with dry density of $1670 \mathrm{~kg} \mathrm{~m}^{-3}$ ) is representative of their findings. In this test, gas breakthrough occurred at an excess gas pressure just fractionally larger than the calculated swelling pressure of the clay, further indicating the importance of swelling pressure on the gas migration process, within initially saturated buffer clays.

As with Pusch and Forsberg (1983), the gas contents of these bentonite samples were found to be very low after gas injection, indicating flow not through the original pore space of the watersaturated bentonite, but via a number of localized pathways. Horseman and Harrington (1997) argue that gas permeability measured in these tests must therefore be a dependent variable, rather than a material property. As such, gas permeability was related to the number of pressure-induced pathways allowing gas migration from the upstream to downstream filter, together with the width, aperture and distribution of these features. Finally, a number of post-test samples were immersed in a beaker of glycerol and gently heated to expand and release helium trapped along the flow pathways. Streams of gas bubbles were observed emerging at numerous discrete points on all surfaces of the clay. As helium solubility in clay porewater is extremely low, it was argued that this represented further evidence for the movement of gas through the clay as a discrete phase, following multiple localized pathways. No emergent gas bubbles were observed in a previous control experiment on fresh bentonite (Harrington and Horseman, 1999).

More recently, a volumetrically confined cell was used by Arnedo et al. (2008) to examine gas migration through mixtures of sand and bentonite. To encourage the creation of preferential pathways for gas migration, air was injected at a constant rate and retrieved from samples by two needles inserted into the base and top of the sample. Observations made through the perspexwalled pressure cell during the experiment indicate the opening of a number of pathways along the interfaces between compaction layers within the bentonite. The authors suggest that such layering could be involved in the gas transportation process. Similar conclusions have also been drawn for gas injection tests involving a number of other low permeability argillaceous materials. Harrington et al. (1999) attributed their observations for gas flow in Boom Clay to the same mechanism. In addition, Angeli et al. (2009) observed a significant drop in ultrasonic P-wave velocity across a sample of Draupne shale during injection of $\mathrm{CO}_{2}$, which correlated with a clear change in volumetric strain. The authors also attributed these observations to gas migration by the formation of dilational pathways. At the field scale the in situ testing of a borehole seal, consisting of compacted bentonite blocks, is described by Van Geet et al. (2007). Gas was injected into the host clay formation in close proximity to the seal, and the pressure increased incrementally. A breakthrough pressure of $3.1 \mathrm{MPa}$ was recorded, closely matching the measured radial stress on the seal due to swelling, prior to the initiation of gas injection.

In this paper we build on previous observations and focus on a series of laboratory and field-scale gas injection tests, carried out on compacted Mx80 bentonite, and highlight a number of key findings. The laboratory experiments referred to in this paper were carried out by Harrington and Horseman (2003) and Horseman et al. (2004). The field experiment discussed relates to the work of Harington et al. (2007) and Cuss et al. (2010, 2011). We highlight and discuss relevant findings from these tests, and describe a conceptual model for advective gas transport in bentonite. This evidence demonstrates the significance of swelling pressure, in relation to the expected gas entry pressure, and the importance of dilatant pathway formation as a mechanism for gas flow. Finally the implications for numerical modelling of these processes, and the consequences for performance assessment of the engineered barrier system, are also discussed.

\section{Approach}

\section{Laboratory}

The laboratory-scale experiments described here were carried out by Harrington and Horseman (2003), and Horseman et al. (2004), using (in contrast to previous isotropic experiments) a custom-designed constant volume and radial flow (CVRF) cell, constructed to examine the sensitivity of gas flow in buffer bentonite to the applied boundary conditions. The apparatus was designed to reproduce some of the main features of the repository near-field, including the borehole, the corroding canister and conductive fractures in the host rock (which were simulated by using arrays of filters as potential sinks for migrating gas).

Their apparatus had the following six main components: (1) a thick-walled stainless steel 
pressure vessel; (2) a fluid injection system; (3) three independent back-pressure systems, each consisting of an array of four filters (sink arrays [1], [2] and [3] in Fig. 1); (4) five total stress sensors to measure radial and axial stress; (5) independent porewater pressure sensors; and (6) a logging system. The relative positions of the stress sensors are shown in Fig. 1 (labelled PT1, $2,3,5$ and 6 , respectively) and an additional independent porewater pressure sensor is denoted as PT4. A final filter was embedded at the end of an injection rod, allowing injection of the permeant directly into the middle of the test sample. High precision syringe pumps were used to control pressure and flow rate of the test fluids. Helium was used as permeant in place of hydrogen, due to its similar characteristics, and its greater suitability for laboratory testing.

The experiments reported by Harrington and Horseman (2003) were carried out on two cylindrical samples $(60 \mathrm{~mm}$ diameter and $120 \mathrm{~mm}$ in length) of compacted Mx80 bentonite (Mx80-8 and Mx80-10). Table 1 (compiled from Harrington and Horseman, 2003) shows the basic physical properties of the specimens tested. The samples were weighed before and after testing,

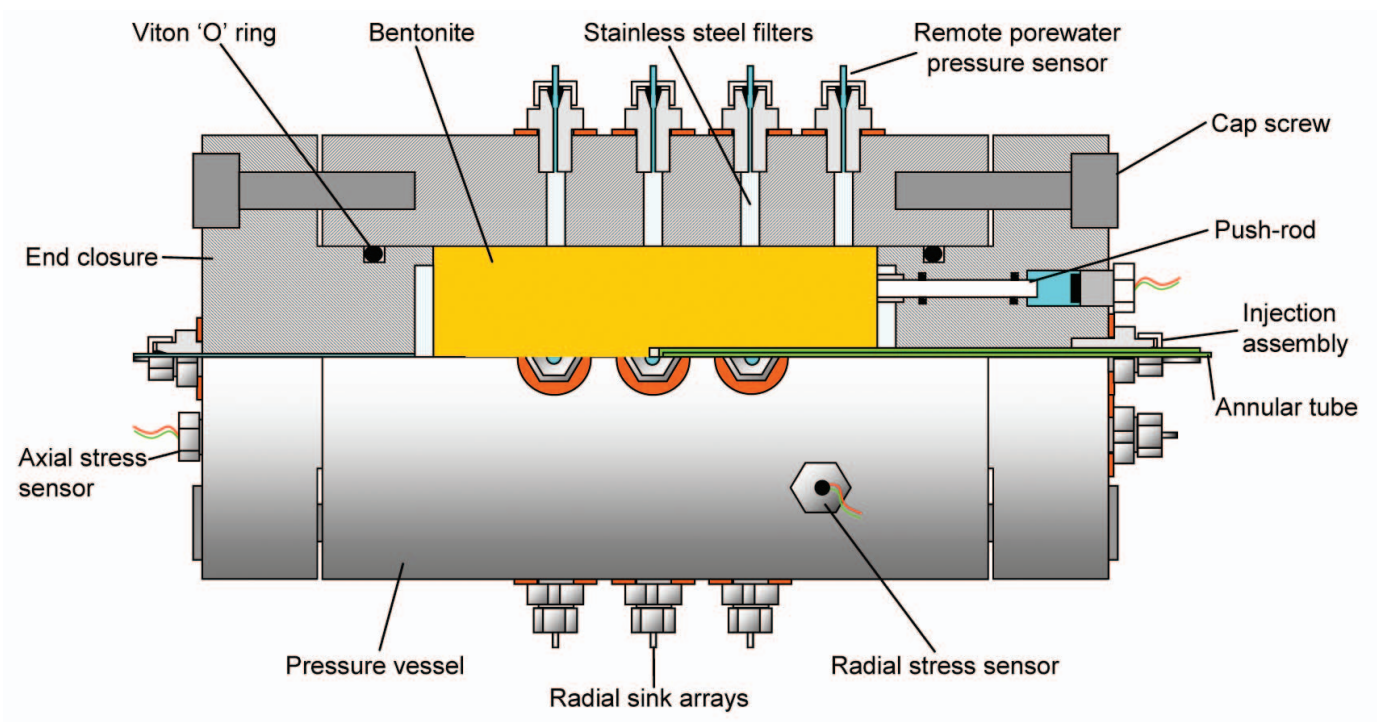

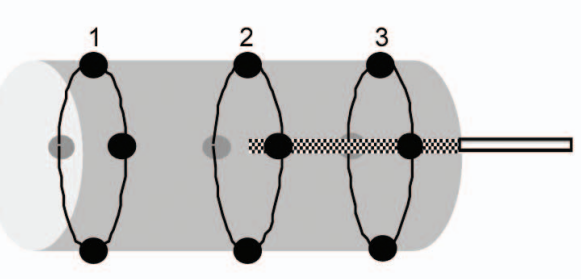

Sink configuration

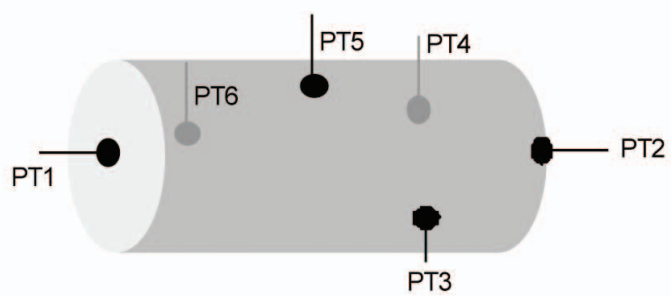

Stress sensor locations

FIG. 1. Cut-away section of the constant volume radial flow (CVRF) cell, showing the two end-closures with their embedded drainage filters, the central fluid injection filter, the twelve radial sink filters, the five total stress sensors and the independent porewater pressure sensor. Sensors are as follows: [PT1], axial total stress on the back-pressure end-closure; [PT2], axial total stress on the injection end-closure; [PT3], radial total stress close to the injection endclosure; [PT4], porewater pressure close to the injection end-closure; [PT5], radial total stress at the mid-plane; and [PT6], radial total stress close to the back-pressure end-closure. 


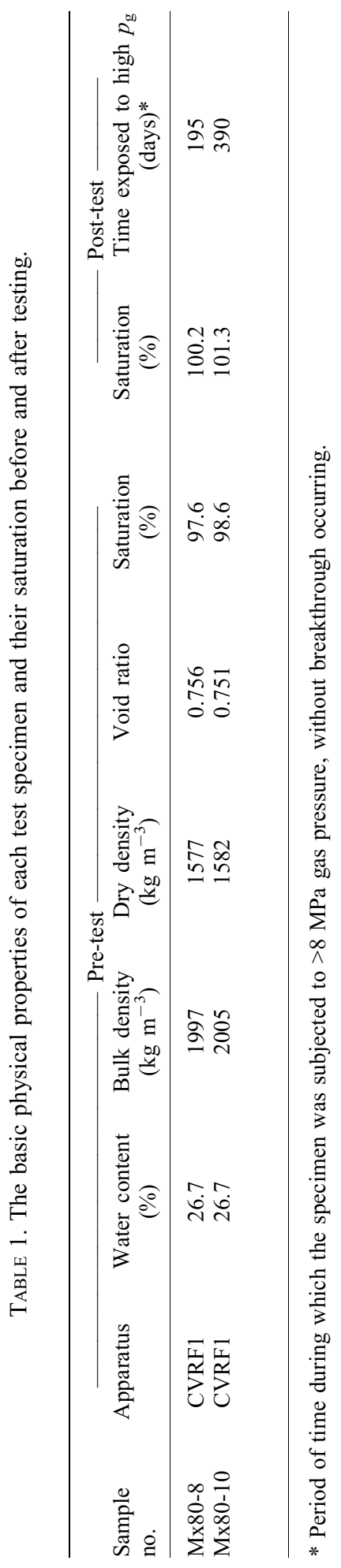

then oven-dried and weighed again. Sample void ratio, porosity and degree of saturation could then be determined based on an average grain density for the bentonite (of $2770 \mathrm{~kg} \mathrm{~m}^{-3}$ ). The test histories involved were exceptionally long in duration (gas testing lasted 224 days and 558 days for Mx80-8 and Mx80-10, respectively), involving many steps, including hydraulic and gas flow testing. Comprehensive information relating to the test programmes is detailed in Harrington and Horseman (2003). Here, we aim to synthesize key findings from the laboratory tests, to make a comparison with field-scale testing and highlight observations that underlie a conceptual model for gas flow in Mx80 bentonite.

Field

The field experiment described by Harrington et al. (2007), Cuss et al. (2010) and Cuss et al. (2011) was designed to simulate the generation of gas from a full-scale canister, surrounded by a buffer of compacted Mx80 bentonite (as in the Swedish KBS-3V repository concept). At the time of writing, this test had been running for 7 years, and included an initial hydration phase, three hydraulic tests and three gas injection tests. A full description of the methodology involved is provided by Harrington et al. (2007) and detailed observations from testing are provided by Cuss et al. (2011). They report that in a typical test, gas was injected through one of 13 filters located on the outside surface of the canister. The evolution of the system was then monitored using 32 total stress sensors and 26 porewater pressure sensors distributed on the canister, in the bentonite and on the rock wall. In the 'field-scale observations' section we highlight some of the key features from gas testing at this scale, as reported by the authors, and make comparison to the laboratory findings to date.

\section{Laboratory-scale observations Hydration/Swelling}

Tests Mx80-8 and Mx80-10 were initiated with a hydration stage, during which the specimens were exposed to deionized water through all filters at a pore-fluid pressure of $1 \mathrm{MPa}$. In response to this boundary condition the sample was observed to swell, leading to an increase in the monitored radial and axial stresses in the material. The data presented by Harrington and Horseman (2003) exhibit some degree of heterogeneity in the 
monitored stresses, which may relate to a number of factors including friction and/or localized variations in the fabric of the sample. As the samples approached hydraulic equilibrium, the measured stresses were observed to asymptote, and inflow at the pore-fluid pump tailed off. Comparison of the expected inflow, based on the pre-test geotechnical data (Table 1), against the total measured inflow over this stage provided confirmation that samples were fully hydrated and at equilibrium before gas testing was begun.

In test Mx80-10, this stage was repeated for incrementally stepped pore-fluid pressures, in order to elucidate the sensitivity of total stress, $\sigma$, to the porewater pressure, $p_{\mathrm{w}}$, within the bentonite. In addition, hydraulic permeability of the bentonite was also investigated for sample Mx80-8. The results of these tests are presented by Harrington and Horseman (2003), but are not discussed further in this paper, as the focus of interest is the gas injection tests.

\section{Gas migration behaviour}

In this section we present a synthesis of the key features noted by Harrington and Horseman (2003), during gas testing of the two samples described. In both cases, gas was injected through the central rod filter, whilst a constant backpressure, $p_{\mathrm{w}}$, of $1 \mathrm{MPa}$ was maintained through one of the large end-closure filters.

\section{Pre-gas breakthrough $\left(p_{g}<\sigma\right)$}

The authors reported that, in both of the laboratory experiments, no evidence was found for the displacement of water as the result of visco-capillary flow in advance of gas migration. Table 1 shows the saturation of the samples before and after each experiment. For both specimens, the measured water content clearly increased over the course of gas testing (the probable result of resaturation of the starting material during the hydration phase). During the course of gas testing, samples Mx80-8 and Mx8010 were exposed to gas pressures greater than 8 $\mathrm{MPa}$, for 195 days and 390 days, respectively. Harrington and Horseman (2003) also calculated that 50.5 litres (for Mx80-8) and 60.4 litres (for Mx80-10) of gas (at STP) had been allowed to pass through the specimens over this time. These data clearly demonstrate that significant quantities of helium can be passed through specimens of buffer clay without any measurable desaturation occurring. This strongly reinforces previous observations of the absence of desaturation during gas flow in Mx80 bentonite (Pusch and Forsberg, 1983; Harrington and Horseman, 1999) and is highly indicative of localized gas migration of gas through the bentonite.

\section{Breakthrough behaviour $\left(p_{g}>\sigma\right)$}

For both tests reported by Harrington and Horseman (2003), gas testing was initiated by injecting helium through the central rod at a constant flow rate of $375 \mu \mathrm{h} \mathrm{h}^{-1}$, allowing the gas pressure to rise, whilst the applied back-pressure was held constant at $1 \mathrm{MPa}$. In the case of Mx808, major gas entry occurred at a gas pressure of 18.9 $\mathrm{MPa}$, followed by breakthrough at a gas pressure of $19.4 \mathrm{MPa}$, when significant outflow of gas began at sink array [1]. For Mx80-10, constant flow rate injection was interspersed with a number of constant gas pressure steps, to examine any time-dependency in the system. When breakthrough finally occurred, the detected outflow was not uniformly distributed across all three sink arrays.

Here we describe some of the key features observed by the authors during breakthrough. In both tests, major gas entry occurred close to the value of the average measured total stress and is accompanied by notable changes in the monitored stresses and porewater pressures (Fig. 2). Test Mx80-10 also exhibited clear step-like stress responses during the approach to failure (Fig. 2a), but no corresponding discharges were observed to the sink arrays indicating that at that time, none of the induced pathways intersected any of the sink filters. These observations indicate that a significant difference between the measured stresses and the applied gas pressure can be achieved before breakthrough occurs (Fig. 2b).

We interpret the observed behaviour in both tests as being the result of advective gas flow through dilatant pathway formation. Such behaviour is consistent with the coupling between the monitored stresses and gas injection pressure observed by Harrington and Horseman (2003) in the post-breakthrough phase. This also suggests that the step-like stress responses detected in Mx80-10 are the result of discrete pathway propagation events. Outflow of gas was also observed by the authors to generally be nonuniformly distributed between the sink arrays, further highlighting the localized nature of its transport. For example, Fig. $3 a$ demonstrates that breakthrough may result in significant outflow to a dominant sink array, rather than being 


\section{GAS MIGRATION EXPERIMENTS IN BENTONITE}
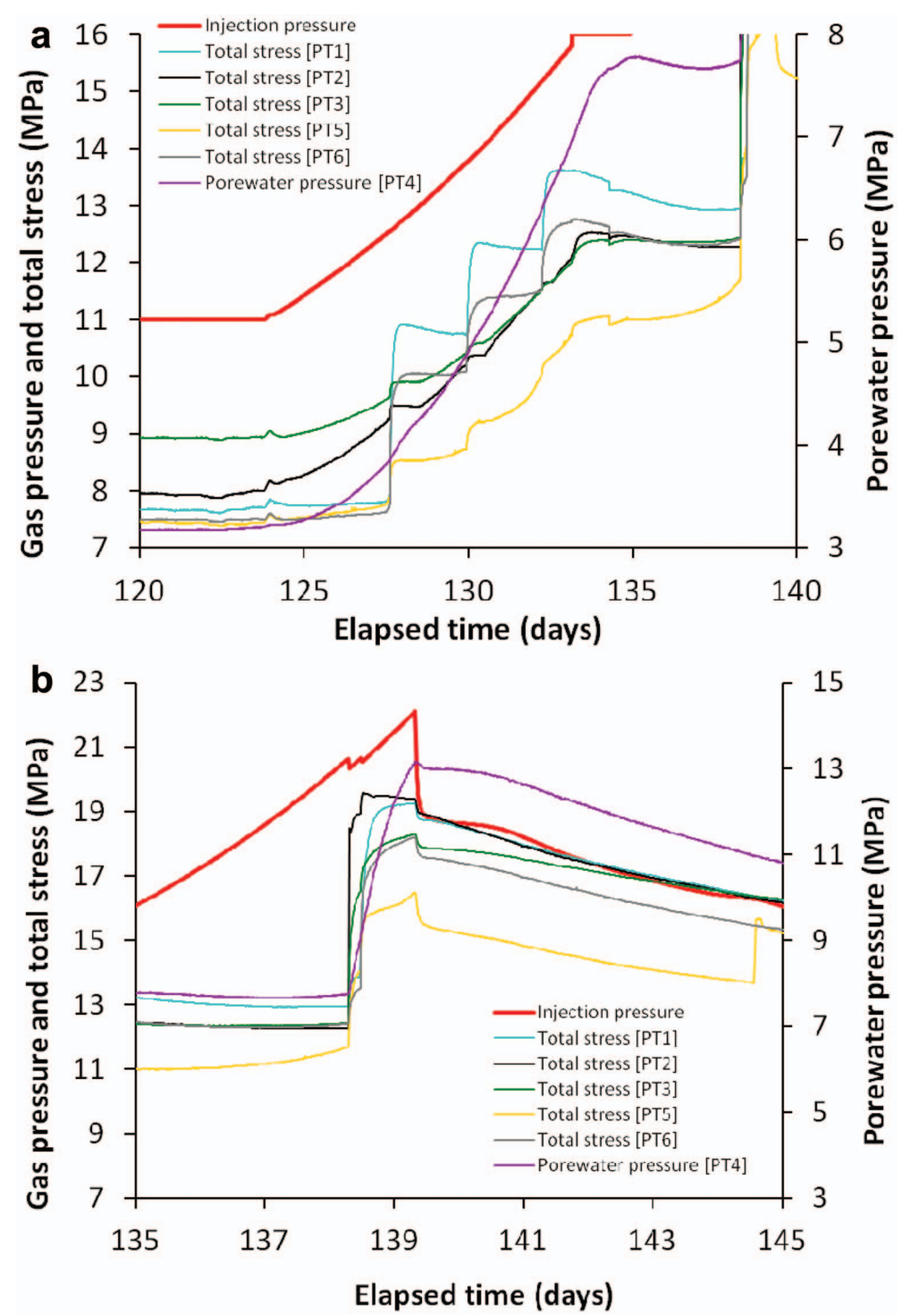

FIG. 2. Major gas breakthrough is accompanied by notable changes in the monitored stresses and porewater pressures, as shown for test Mx80-10. (a) Clear step-like responses in the monitored stresses were observed during the approach to failure, which can be interpreted as distinct pathway propagation events. $(b)$ A notable difference between the total stresses measured in the bentonite and the applied gas pressure can be maintained before breakthrough, at which time this difference becomes minimal.

distributed across all three sinks (as reported for test M80-8). Where gas was initially seen to fail in finding a sink, this led to the generation of very high gas pressures, as a result of the constant volume geometry (as in Fig. 2b). Such behaviour indicates that the number and geometry of available sinks will have a profound effect on the maximum gas pressure that is likely to be sustained by the bentonite buffer at the full canister scale. 

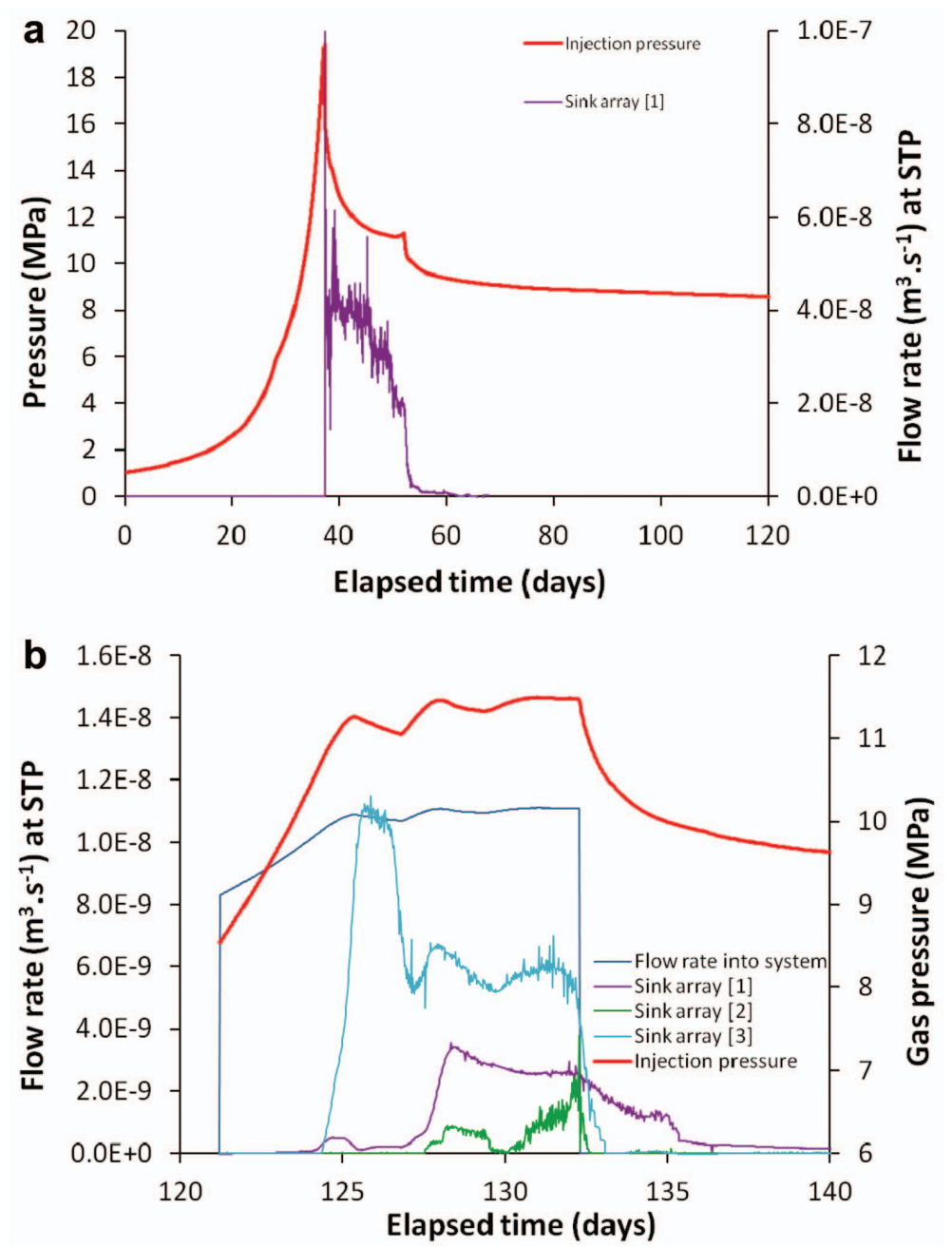

FIG. 3. Experimental data exhibit significant evidence for localized and unstable migration of gas, as demonstrated with data from test Mx80-8. (a) In test Mx80-8, initial breakthrough was correlated with sink array [1], whilst outflow to sink arrays [2] and [3] was negligible. (b) During a successive gas injection stage in test Mx80-8, breakthrough was associated with outflow now to sink array [3], indicating that previously utilized pathways (in this case to sink array [1]) may not necessarily be reutilized in later gas migration events. The distribution of flow changes abruptly and spontaneously during the course of the experiment, with the dominant outflow signal 'switching' from one sink to another. This indicates that localized flow is unstable, with a temporally evolving distribution of migration pathways.

\section{Post-breakthrough behaviour/quasi-steady- state $\left(p_{g} \sim \sigma\right)$}

In both of the tests described by Harrington and co-workers, the post-peak pressure response generally displays a clear change in slope from positive to negative, characteristic of first breakthrough events, as reported in previous studies (Harrington and Horseman, 1999; Horseman et al., 1999). As described above, the gas pressure after gas entry, but before the pressure peak, can rise to exceed the total stress by a significant amount (under constant volume conditions). In marked contrast to this, after breakthrough occurs the authors observed the gas pressure to settle close to the measured total stress, which is seen to be offset from the measured porewater pressure 
(PT4) by an amount similar to the swelling pressure. These findings suggest that the sharp pressure drop after the peak results from a breakdown in the tensile strength of the bentonite and implies that gas pressures observed above the total stress, prior to this, are the consequence of the inability of gas to find a sink. Harrington and Horseman (2003) also report that after breakthrough, a pronounced coupling between $p_{\mathrm{g}}, \sigma$ and $p_{\mathrm{w}}$ is observed, for both samples, made evident by clearly correlated changes in slope (Fig. 4). In addition to this, abrupt reductions in gas injection pressure were observed, accompanied by similar reductions in total stress, which can be interpreted as fracture propagation events. The first fractures that form in the clay may not intersect gas sinks and additional gas pressure may, therefore, be needed to produce fullyconductive fractures which result in outflow. The authors also note that where the test geometry provided a number of possible sinks for gas, measured outflows were always non-uniformly distributed between these sinks (Fig. 4). The distribution of flow was also commonly seen to change abruptly and spontaneously during the experiments, as localized flow was observed to 'switch' from one sink array to another, as demonstrated by Fig. $3 b$. Evidence from the laboratory tests of Harrington and Horseman (2003) also indicates that previous pathways may not necessarily be reused as conduits for future flow. These observations are all consistent with the development of a relatively small number of conductive pathways through the clay. Such features clearly exhibit a degree of instability, resulting in dynamic flow behaviour as their spatial distribution evolves with time.

\section{Shut-in response}

The authors also describe the impact of switching off the gas injection pump after breakthrough has occurred, whereby the pressure was allowed to decay (termed the 'shut-in response') and the rate of outflow was seen to decline with time. As inflow and outflow ceased, the gas pressure approached an asymptotic value that is representative of the minimum pressure at which gas is mobile in the clay (Fig. 5). They also report that during a shut-in phase the final gas pressure arrived at, for both Mx80-8 and Mx80-10, was seen to exceed the monitored porewater pressure by an amount equal to the swelling pressure. The reduction in gas pressure during the shut-in stage reflects a similar reduction in the internal porewater pressure, with the two offset by an amount similar to the measured swelling pressure value. This observed shut-in response can be interpreted as being the result of the collapse of flow pathways as pressure declines.

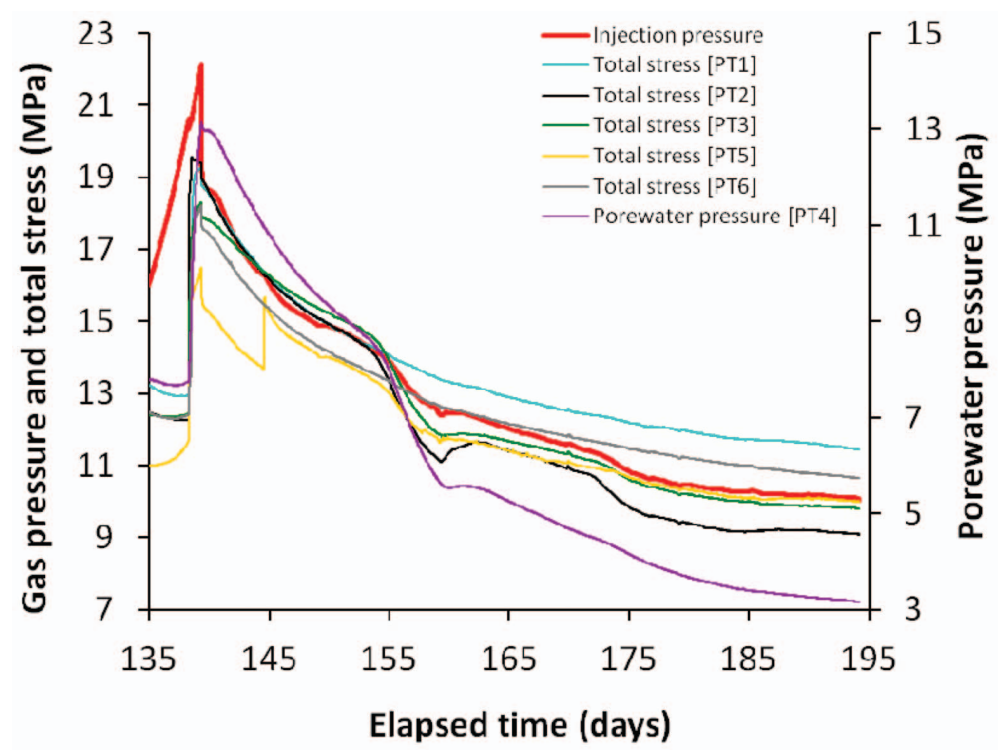

FIG. 4. In the post-breakthrough stage, test data (Mx80-10 shown here) exhibit clearly correlated changes in slope, indicating strong coupling between the monitored porewater pressures, total stresses and gas pressure. 


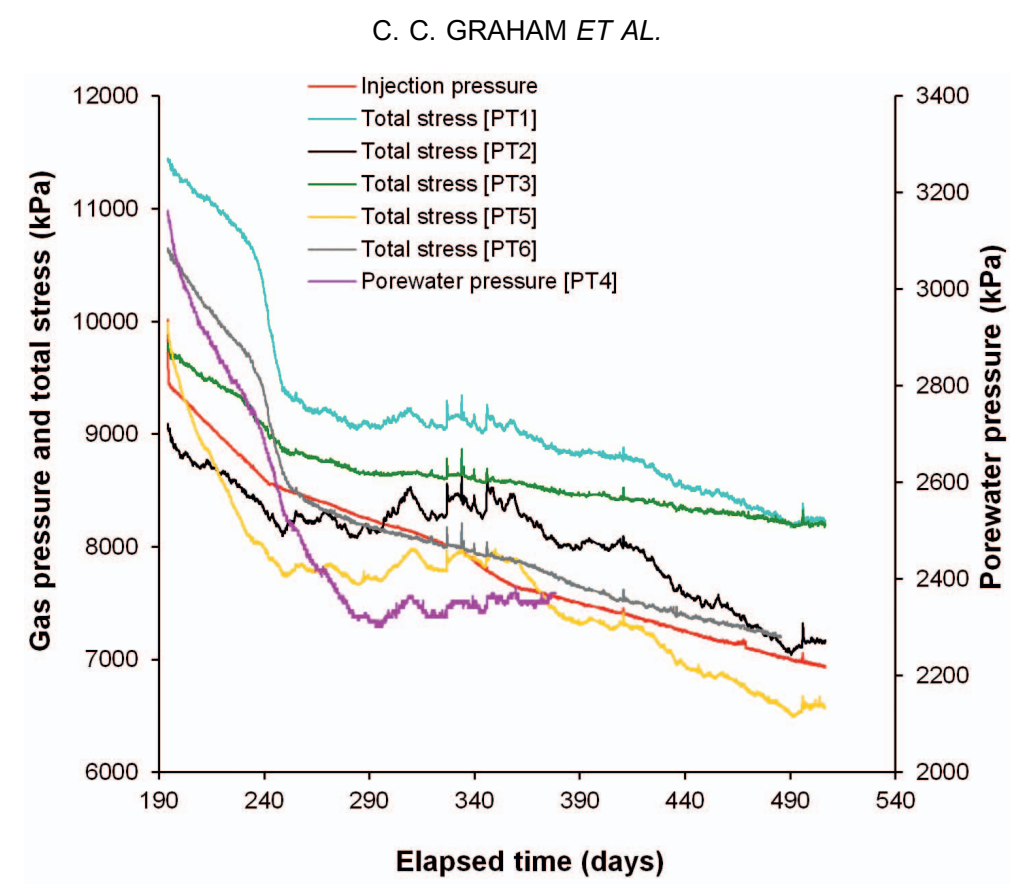

FIG. 5. The 'shut-in response' observed for sample Mx80-10, as described by Harrington and Horseman (2003). After breakthrough had occurred, the gas injection pump was switched off and the pressure allowed to decay. As inflow and outflow ceased, the gas pressure approached an asymptotic value that is representative of the minimum pressure at which gas is mobile in the clay.

\section{Self-sealing behaviour}

Although the laboratory evidence described so far is in support of gas flow through a network of pressure-induced pathways, Harrington and Horseman et al. (2003) also state that no clear evidence was found in these tests for any significant displacement of water during gas movement. Instead, it seems likely that the rupture-like pathways are held open by the elevated gas pressure. When this pressure falls, individual pathways can snap shut, leading to a reduction in the overall gas permeability of the material. In such a scenario, spontaneous changes in the slope of the pressure transients and temporal variations in the amount of gas discharged to sinks, collectively demonstrate the unstable nature of the pathways. Harrington and Horseman also report that a repeat gas injection phase, carried out for sample Mx80-10, provides further insight into potential pathway behaviour after closure. After the first cycle of gas injection, a hydraulic flow test was carried out before a further gas test was initiated. The gas pressure curves generated in this subsequent injection phase indicate that the clay regained some of its original tensile strength, as the result of a period of gas displacement and rehydration. Such spontaneous closure of gas conducting pathways and re-establishment of strength in tension can each be interpreted as a capacity for 'self-sealing'.

\section{Field-scale observations}

In this section, we focus on key findings from a field scale gas injection test, as presented by Cuss et al. (2010) and Cuss et al. (2011). The authors provide a detailed description and interpretation of their results, but here we highlight observations which relate to, and allow comparison with, the laboratory scale tests described in the previous section. In 2005 a full-scale gas injection test (based on the KBS-3V repository concept) was begun at the Äspö hard rock laboratory, to examine gas migration behaviour in a full-scale deposition hole. In contrast to the conceptual model described so far, gas was observed to move at pressures below the total stress. Hydration was still ongoing within the buffer at that time, and this behaviour is interpreted as being associated with the incomplete homogenization of the clay, 
resulting in hydraulic disequilibrium and/or low density zones leading to the localization of flow. However, as with the laboratory scale tests described above, the authors observe that major gas entry was not seen to occur until pressures close to the total stress were reached. The likelihood of gas entry occurring at the immediate location of a stress sensor is low. However, these stress data do provide a very important indicator of the stress levels in the clay during gas migration. The associated increase in flow was also reported to correlate with notable changes in the monitored borehole stresses and porewater pressures (Fig. 6) indicating that major gas entry also occurred through dilatant pathway formation. As seen in the laboratory, these changes were

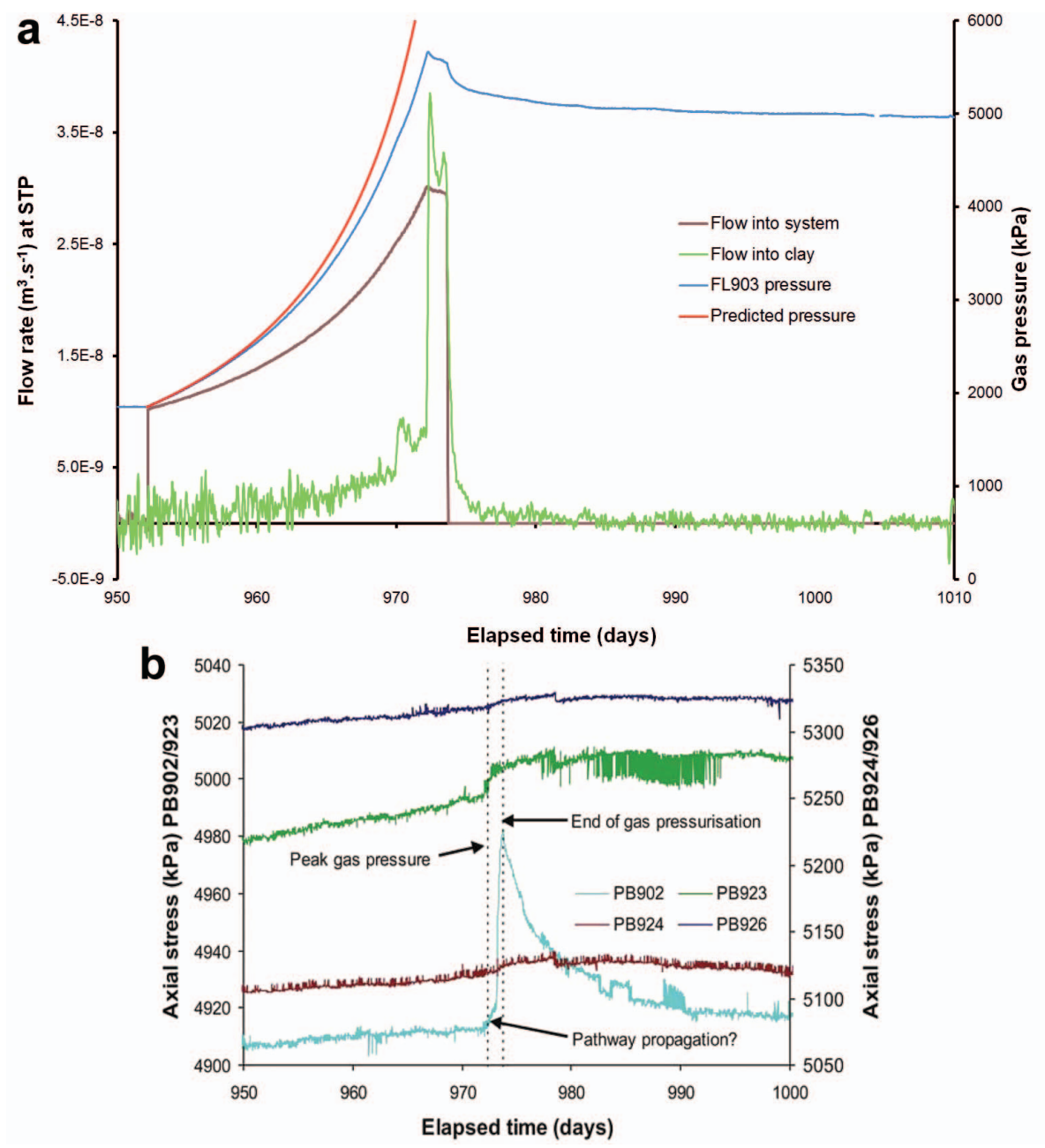

Fig. 6. (a) Data from an early gas injection test from the Lasgit experiment (Cuss et al., 2011) showing STP flow rates into the injection system and the clay, as well as measured and predicted gas pressures, plotted against elapsed time. Flow into the clay is calculated using a combination of weighted moving average and time moving average (mean). The peak pressure response is symptomatic of the development of 'major' gas pathways within the bentonite and is qualitatively similar in response to small-scale experiments reported by Horseman and Harrington (2004). (b) The monitored response to gas breakthrough at four of the stress sensors. As with the laboratory-scale tests described by Harrington and Horseman (2003), a clear correlation was observed between localized changes in the monitored stresses and pore-fluid pressures. A notable time-dependency is also evident in these changes, indicative of the evolution of gas migration pathways. 
highly localized in nature (Fig. 6b) suggesting a relatively small number of pathways were likely to have formed. In addition, the authors also reported temporal variations in monitored stresses, pore-pressures and gas inflow, symptomatic of the time-dependent development of pathways. As at the laboratory scale (described above and in Horseman et al., 1999) major gas entry was characterized by a change in flow rate, from positive to negative in slope, leading to a period of quasi-steady-state behaviour (Fig. 6). Furthermore, during the shut-in phase gas pressure was allowed to decay and settled at an asymptotic value close to that of the measured total stresses. Similar to laboratory observations, instances of pathway 'migration' were clearly inferred from changes in the monitored stresses and porewater pressures. The authors argue that the observed flux is dynamic throughout the test, suggesting a significant degree of instability in the system, which is accompanied by clear inflections in stress and porewater pressure responses. Successive gas testing also demonstrated a nonuniqueness to the path taken by gas as it passes through the bentonite. As such, the gas migration behaviour exhibited on the field scale at Lasgit clearly demonstrates a number of characteristics predicted on the laboratory scale and conforms to the interpretation of gas flow by dilatant pathway formation.

\section{Discussion and implications}

In this paper we examine results from previous gas injection tests on compacted Mx80 bentonite, at both laboratory and field scales. These tests provide key information on the coupling between porewater pressure, gas pressure and total stress. We interpret the behaviour observed in these laboratory and field-scale tests as gas migration through bentonite by the dilatant formation of pathways. This is consistent with previously described observations of gas flow in bentonite (Pusch and Forsberg, 1983; Horseman and Harrington, 1997; Horseman et al., 1999; Donohew et al., 2000; Marschall, et al., 2005; Arnedo et al., 2008) and a number of other argillaceous materials (Horseman et al., 1999; Angeli et al., 2009; Skurtveit et al., 2010). Recent findings described in companion papers in this special issue of Mineralogical Magazine suggest that such a mechanism may be found in a range of low permeability materials. Cuss and Harrington (2011) and Harrington et al. (2012a) present experimental evidence for an associated volumetric deformation of a Callovo-Oxfordian shale sample during gas breakthrough, which they attribute to pathway formation. In addition, Harrington et al. (2012b) demonstrate the use of a new nanoparticle tracer technique, to elucidate the spatial distribution of gas flow during breakthrough testing in Boom Clay, and present the first direct observations of localized gas migration in an argillaceous material.

The evidence from these studies supports our interpretation of the tests described in this paper, for advective gas flow in bentonite, with the following key features: (1) major gas entry occurs at a pressure in close proximity to that of the observed total stress; (2) pronounced coupling between $p_{\mathrm{g}}, \sigma$ and $p_{\mathrm{w}}$ is evident after major gas entry has occurred; (3) flow is localized and ephemeral, exhibiting notable spatio-temporal evolution; and (4) after shut-in, gas pressure decays asymptotically towards a value close to that of the total stress. The results from these studies support the hypothesis that gas flow (at expected in situ pressures) does not take place below the sum of the swelling pressure and porewater pressure. This is consistent with the findings of previous studies in clay (Tanai et al., 1997; Pusch et al., 1985) and can be explained by the need to exceed the strength of the sample for flow to take place. These pathways exhibit unstable behaviour, leading to quasi-dynamic flow, as gas migrates or switches between pathways. Pathways also appear to be nonunique in nature, closing as gas pressure is allowed to decay, but not necessarily being reused as conduits for subsequent gas migration events. This suggests that their distribution may be arbitrary, although they are probably controlled by the most suitable preferential weakness available in the material at a given time. In order to fully represent this behaviour a more detailed understanding of the spatial distribution of these pathways, the controls on their behaviour and their temporal development, is required. Such behaviour makes conventional concepts of twophase flow poorly suited to adequately represent the key processes involved for Mx80 bentonite. Although dilatancy-based models provide a better description of such processes, the paucity of data at present limits further development and validation of these models.

Similarities in gas flow behaviour are observed in both the laboratory and field scale tests. However, the very high gas pressures that can 
be observed in the laboratory, due to the potential for gas to initially fail in finding a sink, highlight the geometry dependence of such tests. In contrast, such extremes in behaviour are likely to be moderated at the field scale by the presence of interfaces, heterogeneities and the compressibility of the clay. Long-term results from Lasgit should provide evidence for this, once the system achieves hydraulic equilibrium. The findings of this test programme indicate that for an engineered barrier consisting of compact bentonite, localization of gas flow may well need to be considered in some safety-case scenarios. Advective gas flow under such conditions is clearly associated with preferential pathway migration. Such behaviour is currently not well represented with classic porous-media models (based on visco-capillary flow) and any such numerical approach should encapsulate the characteristic hydromechanical coupling observed in such situations. This will require a greater understanding of the spatial distribution of gasconducting pathways, and their development with time, than is available at present. As such, a demonstrative approach, utilizing the appropriate conceptual model for gas flow, has an important role to play in performance assessment.

\section{References}

Angeli, M. Solday, M., Skurtveit, E. and Aker, E (2009) Experimental percolation of supercritical $\mathrm{CO}_{2}$ through a caprock. Energy Procedia, 1, 3351-3358.

Arnedo, D., Alonso, E.E., Olivella, S. and Romero, E. (2008). Gas injection tests on sand/bentonite mixtures in the laboratory. Experimental results and numerical modelling. Physics and Chemistry of the Earth, 33, S237-S247.

Cuss, R.J. and Harrington, J.F. (2011) Update on Dilatancy Associated with Onset of Gas Flow in Callovo-Oxfordian Claystone. Progress report on test SPP_COx-2. British Geological Survey commissioned report $\mathrm{CR} / 11 / 110,34 \mathrm{pp}$.

Cuss, R.J., Harrington, J.F. and Noy, D.J. (2010). Large Scale Gas Injection Test (Lasgit) Performed at the Äspö Hard Rock Laboratory. Summary Report 2008. Svensk Kärnbränslehantering $\mathrm{AB}$ (SKB) Technical Report TR-10-38. SKB, Stockholm, Sweden, 109 pp.

Cuss, R.J., Harrington, J.F., Noy, D.J., Wikman, A. and Sellin, P. (2011) Large scale gas injection test (Lasgit): results from two gas injection tests. Physics and Chemistry of the Earth, 36, 1729-1742.

Donohew, A.T., Horseman, S.T. and Harrington J.F. (2000) Gas entry into unconfined clay pastes between the liquid and plastic limits. Pp. 369-394 in: Environmental Mineralogy - Microbial Interactions, Anthropogenic Influences, Contaminated Land and Waste Management (J.D. Cotter-Howells, L.S. Campbell, E. Valsami-Jones and M. Batchelder, editors). Mineralogical Society Special Publication, 9. Mineralogical Society of Great Britain and Ireland, London.

Gallé, C. (1998) Migration des gaz et pression de rupture dans une argile compactée destinée à la barrière ouvragée d'un stackage profound. Bulletin de la Société Géologique de France, 169, 675-680.

Gallé, C. and Tanai, K. (1998) Evaluation of gas transport properties of back fill materials for waste disposal: $\mathrm{H}_{2}$ migration experiments in compacted Fo-Ca Clay. Clays and Clay Minerals, 46, 498-508.

Harrington, J.F. and Horseman, S.T. (1999) Gas transport properties of clays and mudrocks. Pp. 107-124 in: Muds and Mudstones: Physical and Fluid Flow Properties (A.C. Aplin, A.J. Fleet and J.H.S. Macquaker, editors). Geological Society of London Special Publication, 158. Geological Society of London, London.

Harrington, J.F. and Horseman, S.T. (2003) Gas Migration in KBS-3 Buffer Bentonite: Sensitivity of Test Parameters to Experimental Boundary Conditions. SKB Technical Report No. TR-03-02. Svensk Kärnbränslehantering $\mathrm{AB}$, Stockholm, Sweden.

Harrington, J.F., Birchall, D.J., Noy, D.J and Cuss, R.J. (2007) Large Scale Gas Injection Test (Lasgit) Performed at the Äspö Hard Rock Laboratory: Summary Report 2007. British Geological Survey Commissioned Report, CR/07/211.

Harrington, J.F., de la Vaissière, R., Noy, D.J., Cuss, R.J. and Talandier, J. (2012) Gas flow in CallovoOxfordian clay (COx): results from laboratory and field-scale measurements. Mineralogical Magazine, 76, 3303-3318.

Horseman, S.T. (1996) Generation and Migration of Repository Gases: Some Key Considerations in Radioactive Waste Disposal. In: Proc. Int. 2-Day Conference, London, 21-22 Nov. 1996, IBC Technical Services, Energy Division, 26 pp.

Horseman, S.T. and Harrington, J.F. (1997) Study of Gas Migration in Mx80 Buffer Bentonite. British Geological Survey, Technical Report WE/97/7. British Geological Survey, Keyworth, Nottingham, UK.

Horseman, S.T., Harrington, J.F. and Sellin P. (1997). Gas migration in Mx80 buffer bentonite. MRS Symposia Proceedings, 465, 1003-1010.

Horseman, S.T., Harrington, J.F. and Sellin, P. (1999) Gas migration in clay barriers. Engineering Geology, 54, 139-149.

Horseman, S.T., Harrington, J.F. and Sellin, P. (2004) Water and gas flow in Mx80 bentonite buffer clay. 


\section{C. GRAHAM ET AL.}

Materials Research Society, 807, 715-720.

Marschall, P., Horseman, S. and Gimmi, T. (2005) Characterisation of gas transport properties of the Opalinus Clay, a potential host rock formation for radioactive waste disposal. Oil \& Gas Science and Technology - Revue de l'IFP, 60, 121-139.

Pusch, R. and Forsberg, T. (1983) Gas Migration through Bentonite Clay. SKB Technical Report 83-71. Svensk Kärnbränslehantering $\mathrm{AB}$, Stockholm, Sweden.

Pusch, R., Ranhagen, L. and Nilsson, K. (1985) Gas Migration through Mx-80 Bentonite. Nagra Technical Report NTB 85-36. Nagra, Wettingen, Switzerland.

SKB (2011) Long-term Safety for the Final Repository for Spent Nuclear Fuel at Forsmark: Main Report of the SR-Site Project. SKB Technical Report
TR-11-01. Svensk Kärnbränslehantering AB, Stockholm, Sweden.

Skurtveit, E., Aker, E., Soldal, M., Angeli, M. and Hallberg, E. (2010) Influence of Micro Fractures and Fluid Pressure on Sealing Efficiency of Caprock: A Laboratory Study on Shale. GHGT-10. International Conference on Greenhouse Gas Technologies.

Tanai, K., Kanno, T. amd Gallé, C. (1997) Experimental study of gas permeabilities and breakthrough pressures in clays. MRS Symposia Proceedings, 465, 1003-1010.

Van Geet, M., Volckaert, G., Bastiaens, W., Maes, N., Weetjens, E., Sillen, X., Vallejan, B. and Gens, A. (2007) Efficiency of a borehole seal by means of precompacted bentonite blocks. Physics and Chemistry of the Earth, 32, 123-134. 